\title{
Myocardial Revascularization in Renal Transplant Patients
}

\author{
Daniel de Souza Delgado, Luís Roberto Gerola, Nelson Américo Hossne Jr., \\ João Nelson R. Branco, Enio Buffolo \\ São Paulo, SP - Brazil
}

Objective - To assess the results of surgical myocardial revascularization in renal transplant patients.

Methods - From 1991 to 2000, 11 renal transplant patients, whose ages ranged from 36 to 59 (47.5 \pm 8 ) years, 8 males and 3 females, underwent myocardial revascularization. The time interval between renal transplantation and myocardial revascularization ranged from 25 to 120 (mean of 63.8土32.7) months.

Results - The in-hospital mortality rate was $9 \%$. One patient died on the 4th postoperative day from septicemia and respiratory failure. The mean graft/patient ratio was $2.7 \pm 0.8$. Only 1 patient required slow hemodialysis during 24 hours in the postoperative period, and no patient had a definitive renal lesion or lost the transplanted kidney. The actuarial survival curves after 1, 2, and 3 years were, respectively, $90.9 \%, 56.8 \%$, and $56.8 \%$.

Conclusion - Renal transplant patients may undergo myocardial revascularization with no lesion in or loss of the transplanted kidney.

Keywords: coronary atherosclerosis, myocardial revascularization, renal transplantation

Universidade Federal de São Paulo - Escola Paulista de Medicina

Mailing address: Luís Roberto Gerola - Rua Conde de Irajá, 184/15 - 04119-010

São Paulo, SP, Brazil - E-mail: gerola@uol.com.br

English version by Stela Maris C. e Gandour
Cardiovascular disease is the major cause of mortality in patients with advanced chronic renal failure and in those undergoing renal transplantation ${ }^{1-4}$. Several factors, such as hypertension, alterations in lipid metabolism, diabetes, and immunosuppressive therapy, accelerate cardiovascular disease in renal transplant patients and in those undergoing dialysis ${ }^{1-4}$. It is worth noting that myocardial infarction as a cause of death in these patients exceeds $20 \%{ }^{4,5}$.

In addition, Manske et al ${ }^{6}$ reported that in patients with an indication for renal transplantation, in whom myocardial ischemia was identified, myocardial revascularization reduced the risk of renal transplantation and increased immediate survival.

The first myocardial revascularization surgeries in renal transplant patients were performed in the beginning of the $1970 \mathrm{~s}^{7-9}$. Since then, not only have transplantation and immunosuppression techniques greatly developed, but dialytic methods have also. This has resulted in an expressive and progressive increase in these patients' survival, making this population subject to coronary atherosclerotic disease part of the daily routine of cardiovascular surgery services.

This study aimed at assessing the results of myocardial revascularization surgery in renal transplant patients.

\section{Methods}

We carried out a retrospective study in patients with advanced chronic renal disease, who had undergone renal transplantation and, in the postoperative clinical follow-up, developed coronary heart disease and underwent myocardial revascularization. Patients undergoing procedures associated with revascularization were excluded from the study.

From 1991 to 2000, 11 renal transplant patients underwent myocardial revascularization. Their ages ranged from 36 to 59 (mean of $47.5 \pm 8$ ) years; 8 were males and 3 were females. The interval between renal transplantation and myocardial revascularization ranged from 25 to 120 (mean of 63.8 \pm 32.7 ) months.

The indication for myocardial revascularization surgery in these cases did not differ from the usual indications 
in patients with no renal failure. For surgical treatment, the following patients were considered: patients with threevessel disease, those with lesions in the trunk of the left coronary artery, and those with two-vessel disease and lesions close to the anterior interventricular artery.

Associated diseases were observed in 8 patients, hypertension being present in all of them, dyslipidemia in 4 , peripheral vascular disease in 2 , type II diabetes mellitus in 3 , obesity in 1 , and chronic obstructive pulmonary disease in another. Four patients reported tobacco use.

Three patients were in functional class IV for angina, 5 were in functional class III, and 3 were in functional class II. Four patients had experienced previous myocardial infarction, confirmed on electrocardiography (presence of Q wave), 7 patients had symptoms of cardiac failure associated with symptoms of coronary heart disease, 2 (22\%) of whom were in NYHA functional class III and 5 in functional class II.

Coronary angiography showed three-vessel coronary artery disease in $8(66.6 \%)$ patients and two-vessel disease in $3(33.3 \%)$.

Left ventricular function was assessed in the preoperative period with Doppler echocardiography in 6 patients, and in 3 patients the mean ejection fraction was estimated as $0.73 \pm 0.12$ (ranging from 0.61 to 0.85 ). No patient had severe ventricular dysfunction in the preoperative period.

All data are shown as mean \pm standard deviation. Longterm survival was estimated with the Kaplan-Meier method.

\section{Results}

In-hospital mortality was $9 \%$, and 1 patient died on the 4th postoperative day from septicemia and respiratory failure.

The mean graft/patient ratio was $2.7 \pm 0.8$. The left internal thoracic artery was used to revascularize the anterior interventricular artery in $9(77.7 \%)$ patients and the diagonal artery in $2(22.2 \%)$. The great saphenous vein was used to revascularize the other arteries. In 8 patients, the operation was performed with extracorporeal circulation and cardioplegic arrest, and in 3 patients without extracorporeal circulation.

The mean creatinine value in the preoperative period was $2.0 \pm 0.8 \mathrm{mg} / \mathrm{dL}$. Only 1 patient required dialysis in the postoperative period of revascularization, slow hemodialysis for 24 hours. This patient had a significant reduction in urinary output, with hyperpotassemia and signs of pulmonary congestion. We chose to maintain slow hemodialysis in the patient until normalization of renal function and metabolic correction, which happened in the subsequent 24 hours. No patient experienced a definite worsening of renal function or loss of the transplanted kidney, or even perioperative myocardial infarction. One patient had atrial fibrillation with a high ventricular response, which was chemically reverted, and another patient experienced periods of mental confusion.

Three patients had pneumonia, 1 evolved to septicemia and respiratory failure, which was the cause of the only death in this population. Another patient with pulmonary infection required reintubation and had a good evolution.

No hemorrhagic complications or reoperations due to bleeding occurred.

Hospital stay ranged from 11 to 42 days (mean of $19.2 \pm 10$ days), and intensive care unit stay ranged from 2 to 15 days (mean of $4.2 \pm 4.4$ days).

Follow-up ranged from 1 to 90 months (mean of $32.8 \pm 34.4$ months). Eight patients were in functional class I in the postoperative period and the remaining were in functional class II.

Two patients were not followed up in our service, being referred to their original places. One patient died due to enterorrhagia secondary to colonic diverticular disease 23 months after revascularization.

The actuarial survival curves (Kaplan-Meier method) after 1,2 , and 3 years were, respectively, $90.9 \%, 56.8 \%$, and $56.8 \%$ (fig. 1 ).

\section{Discussion}

In this study, myocardial revascularization in renal transplant patients was performed with no subsequent definitive lesions in or loss of the transplanted kidney, pulmonary infection being the major complication observed in the postoperative period.

Several risk factors during and following the surgery have been reported in the literature, factors that may lead to transplanted kidney loss or lesions, among which we can cite hemodynamic alterations occurring due to the use of extracorporeal circulation ${ }^{8}$, hyperpotassemia, drug accumulation, cardiac arrhythmias ${ }^{10,11}$, septicemia, and coagulation disorders ${ }^{11,12}$.

In this study, 3 (27.2\%) patients had pulmonary infection, 1 of whom evolved to septicemia with respiratory fai-

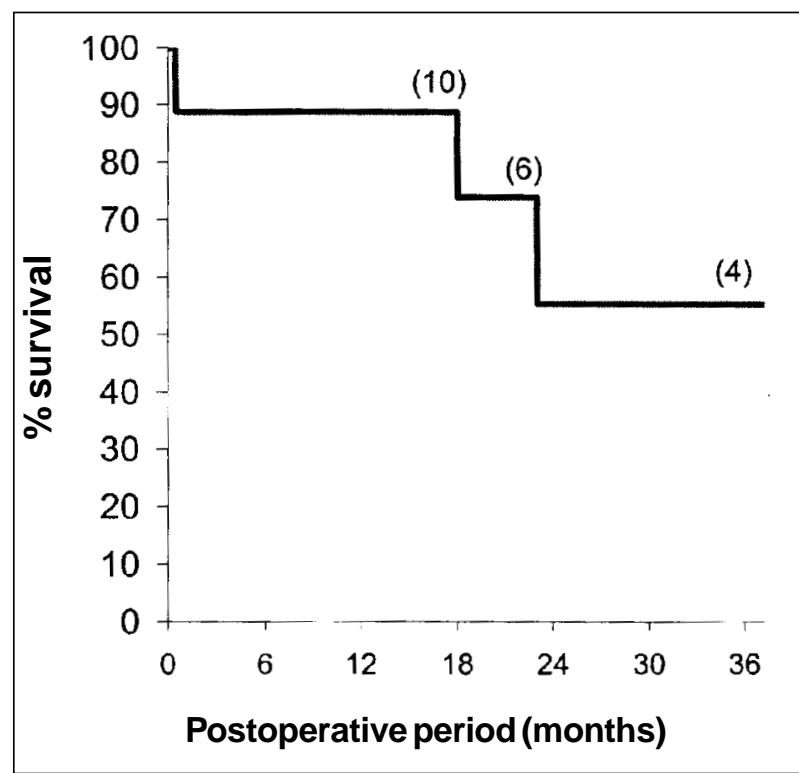

Fig. 1 - Survival curve of the renal transplant patients undergoing myocardial revascularization surgery. 
lure, which was the cause of the only death in this case series. Although the risk of infection should always be kept in mind, reports in the literature are mixed. Bolman et al ${ }^{13}$ reported 3 cases of infection in 14 patients operated on; on the other hand, Christiansen et al ${ }^{14}$, Beauchamp et al ${ }^{9}$ and Chawla et al ${ }^{15}$, in short case series, did not report this complication. It is important to emphasize that the risk of infections in these patients was attributed to the prolonged use of corticoids and immunosuppressants ${ }^{8,10}$.

The first successful myocardial revascularization in a renal transplant patient was reported in 1975 by Nakhjavan et $\mathrm{l}^{8}$ as a case report. Since then, reports on the experience of surgical teams with this type of patient have been scarce, most of them in the form of case reports or small case series (tab. $\mathrm{I}^{7-9,13,14,16-25}$ ).

In 1997, Dresler et al ${ }^{26}$ carried out a study, one of the largest case series in the literature, with 45 renal transplant patients undergoing cardiac surgery, 31 being myocardial revascularization. They reported an in-hospital mortality rate of $8.8 \%$, septicemia being the major cause of death. No patient lost the transplanted kidney in the perioperative period.

The in-hospital mortality rate in our study was $9 \%$, similar to that reported in the literature.

Another important issue regards the use of extracorporeal circulation that represents in this type of patient the major risk for renal ischemia. This risk increases when the duration of extracorporeal circulation exceeds 60 minutes ${ }^{14}$.

In our study, no patient had a definitive lesion in the transplanted kidney, but 1 had a reduction in renal function, requiring slow hemodialysis for 24 hours in the postoperative period. This may have resulted from a reduction in renal perfusion during surgery due to extracorporeal circulation.

Currently, the appearance of minimally invasive surgery, whose major characteristic is not using extracorporeal circulation, is an excellent alternative surgical technique in renal transplant patients. Most of our patients had threevessel disease and were operated on with extracorporeal circulation with no subsequent lesions in the transplanted kidney, because, at that time, no technical alternatives exis-

\begin{tabular}{|c|c|c|c|}
\hline \multicolumn{4}{|c|}{$\begin{array}{c}\text { Table I - List of authors with number of patients and in-hospital } \\
\text { mortality }\end{array}$} \\
\hline Authors & Year & $\mathrm{N}^{\circ}$ patients & Mortality (\%) \\
\hline Nakhjavan et al ${ }^{8}$ & 1975 & 1 & 0 \\
\hline Lamberti et $\mathrm{al}^{7}$ & 1975 & 1 & 0 \\
\hline Beauchamp et al ${ }^{9}$ & 1976 & 3 & 0 \\
\hline Bolman et al ${ }^{13}$ & 1984 & 10 & 10 \\
\hline Golan et al ${ }^{16}$ & 1987 & 1 & 0 \\
\hline Defraigne et al ${ }^{17}$ & 1990 & 1 & 0 \\
\hline Meyer et al ${ }^{18}$ & 1991 & 8 & 0 \\
\hline Yamamura et al ${ }^{19}$ & 1993 & 1 & 0 \\
\hline Ando et $\mathrm{al}^{20}$ & 1993 & 2 & 0 \\
\hline Tezcaner et al 21 & 1996 & 1 & 0 \\
\hline Christiansen et al ${ }^{14}$ & 1999 & 4 & 0 \\
\hline Mitruka et al ${ }^{22}$ & 1997 & 18 & 5,5 \\
\hline Dagenais et al & 1998 & 20 & 10 \\
\hline Noda et al ${ }^{24}$ & 1999 & 2 & 0 \\
\hline Taketani et al ${ }^{25}$ & 2000 & 1 & 0 \\
\hline
\end{tabular}

ted for approaching the left marginal artery without extracorporeal circulation ${ }^{27}$. Because this study had a very small sample, the possible differences between operating on renal transplant patients with or without extracorporeal circulation could not be identified.

Although our data do not allow an effective conclusion about the effects of extracorporeal circulation in the transplanted kidney in the in-hospital and late periods, the current literature has stressed that surgery without extracorporeal circulation has its major benefit in patients with clinical morbidity in the preoperative period ${ }^{28-30}$.

The in-hospital mortality rate in renal transplant patients has been reported as approximately $10 \%$ in the largest case series. We observed that these surgeries have also been performed with extracorporeal circulation, and we believe that this mortality rate may be reduced in the coming years, when most of these procedures will be performed without extracorporeal circulation, and, therefore, with 1 less factor of aggression to the transplanted kidney.

In conclusion, myocardial revascularization in renal transplant patients may be performed with no definitive renal lesion or loss of the transplanted kidney.

\section{References}

1. Burton BT, Kreuger KK, Bryan FA. National registry of long term dialysis patients. JAMA 1971;218: 718-21.

2. Francis GS, Sharma B, Collins AJ, Helseth HK, Comty CM. Coronary artery surgery in patients with end-stage renal disease. Ann Intern Med 1980; 92: 499.

3. Lindner A, Charra B, Sherrard J, Scriber B. Accelerated atherosclerosis in prolonged maintenance dialysis. N Engl J Med 1974; 290: 697.

4. Opsahl JA, Husebye DG, Helseth HK, Collins AJ. Coronary artery bypass surgery in patients on maintenance dialysis: long term survival. Am J Kidney Dis 1988; 12: 271.

5. Frye EB, Vaziri ND, Martin DC, Farooqui S. Cardiovascular pathology in renal transplant recipients. J Nat Med Ass 1986; 78: 1187.

6. Manske CL, Wang Y, Rector T, Wilson RF, White CW. Coronary revascularization in insulin-dependent diabetic patients with chronic renal failure. Lancet 1992; 340: 998.
7. Lamberti JJ, Cohn LH, Collins JJ. Cardiac surgery in patients undergoing renal dialysis or transplantation. Ann Thorac Surg 1975; 19: 135-41.

8. Nakhjavan FK, kahn A, Rosenbaun J, Ablaza S, Goldberg H. Aortocoronary vein graft surgery in a cadaver kidney transplant recipient. Arch Intern Med 1975; 135: 1511-13.

9. Beauchamp GD, Sharma JN, Crouch T, et al. Coronary bypass surgery after renal transplantation. Am J Cardiol 1976; 37: 1107-10.

10. Kuehnel E, Lundn H, Bennet W, Porter G. Aortocoronary bypass surgery in patients with end-stage renal desease. Trans Am Soc Intern Organs 1976;22: 14-20.

11. Lansing AM, Loeb DE, Berman LB. Cardioascular surgery in end-stage renal failure. JAMA 1968; 204: 134-8.

12. Crawford FA Jr, Selby JH Jr, Bower JD, Lehan PH. Coronary revascularization in patients maintained on chronic hemodialysis. Circulation 1977; 56: 684-7.

13. Bolman RM, Anderson RW, Molina JE, et al. Cardiac operation in patients with functioning renal allografts. J Thorac Cardiovas Surg 1984; 88: 537-43. 
14. Christiansen S, Splittgerber FH, MarggraafG, et al. Results of cardiac operations in five kidney transplant atiens. Thorac Cardiovasc Surgeon 1999; 45: 75-77.

15. Chawla R, Gailiunas P, Lasaurus JM, et al. Cardiopulmonary bypass surgery in chronic hemodialysis and transplant patients. Trans Am Soc Intern Organs 1977; 23: 694-7.

16. Golan M, Goor DA, Jacob ET. Coronary artery bypass surgery in cadaver kidney transplant recipient. Int Surg 1987; 72: 565-57.

17. Defraine JO, Meurisse M, Limet R. Valvular and coronary surgery in renal transplant patients. J Cardiovasc Surg 1990; 31: 581-3.

18. Meyer M, Wyns W, Dion R, Khoury G, Pirson Y, van Ypersele de Strihou C. Myocardial revascularization in patients on renal replacement therapy. Clinical Nephrology 1991; 3: 147-51.

19. Yamamura M,Miyamoto T,MurataH,KitaiK,Ueda T, Wada T. A case of myocardial revascularization in a patient renal transplant. Nippon Kyobu Geka Zasshi 1993; 41: 503-08.

20. Ando MH, Koyanagi M, Endo M, Nishida H, Hachida M, Teraoka S. A report of two cases of coronary bypass surgery after renal transplantation. Nippon Kyobu Geka Gakkai Zasshi 1993; 41:2126-30.

21. Tezcaner T, Yorgancioglu C, Molbidi O, Catav Z, Erbay B, Zorlutuna IY. Coronary bypass surgery in a renal transplant patient. Intern Urology Nephrology 1996; $28: 583-7$

22. Mitruka SN, Griffith BP, Kormos RL, et al. Cardiac operations in solid-organ transplant recipients. Ann Thorac Surg 1997; 64: 1270-8.
23. Dagenais F, Voisine P, Normandin L, Martin M, Poirier NL. La chirurgie cardiaque chez le patient greffé rénal: à propos de 24 cas. Annal Chirurgie 1998; 52: 834-9.

24. Noda H, Fijimura Y, Gohra H, Hamano K, Katoh T, Esato K. Coronary bypass surgery after renal transplanttation. Jpn J Thoracic Cardiovascular Surg 1999; 47: $135-40$.

25. Taketani S, Fukushima N, Ohtake S, Sawa Y, Nishimura M, Matusda H. Coronary artery bypass graft in a renal transplant recipient. Jpn J Thoracic Cardiovasc Surg 2000; 48: 542-4.

26. Dresler C, UthoffK, Wahlers T, et al. Open heart operations after renal transplantation. Ann Thorac Surg 1998; 65: 596.

27. Lima RC. Padronização da técnica de revascularização do miocárdio da artéria circunflexa e seus ramos sem circulação extracorpórea. (Tese de Doutorado). Universidade Federal de São Paulo/Escola Paulista de Medicina, São Paulo, SP.

28. Yokoyama T, Baumgartner FJ, Gheissari A, Capouya ER, Panagiotides GP, Declusion RJ. Off-pump versus on-pump coronary bypass in high-risk subgroups Ann Thorac Surg 2000; 70: 1546-50.

29. Güller M, Kirali K, Toker ME, et al. Different CABG methods in patients with chronic obstrutive pulmonary disease. Ann Thorac Surg 2001; 71: 152-57.

30. Ricci M, Karamanoukian HL, Abraham R, et al. Stroke in octagenarians undergoing coronary artery surgery with and without cardiopulmonary bypass. Ann Thorac Surg 2000; 69: 1471-5. 